\title{
VARIASI HARIAN DAN TAHUNAN HUJAN DI SERPONG BERDASARKAN PENGAMATAN DENGAN MICRO RAIN RADAR
}

\author{
Daily and Yearly Rain Variation in Serpong Based on \\ Micro Rain Radar Observations.
}

\author{
Findy Renggono ${ }^{\left.1^{*}\right)}$ \\ 1) Balai Besar Teknologi Modifikasi Cuaca - Badan Pengkajian dan Penerapan Teknologi, Gedung Ir. \\ Mohammad Soebagio, GEOSTECH (820), Kawasan PUSPIPTEK, Serpong, Tangerang Selatan \\ *E-mail : findy.renggono@bppt.go.id
}

\begin{abstract}
Intisari
Kemampuan MRR untuk mengamati profil hujan sampai ketinggian di atas $7500 m$ dapat digunakan untuk mengamati kemunculan jenis hujan. Dari parameter yang diperoleh dapat dibedakan menjadi dua jenis hujan, konvektif dan stratiform berdasarkan keberadaan brightband. Pengamatan kemunculan jenis hujan dengan MRR di Serpong menunjukkan bahwa hujan konvektif relatif muncul lebih banyak dibandingkan stratiform pada puncak musim kering, sedangkan pada musim hujan sebaliknya. Untuk variasi hariannya, puncak hujan konvektif muncul sekitar pukul 15.0016.00 WIB sedangkan stratiform sekitar pukul 18.00 WIB.
\end{abstract}

Kata kunci : Hujan, Konvektif, Stratiform, Micro Rain Radar.

\begin{abstract}
The ability of micorain radar to observe precipitation profiles up to $7500 \mathrm{~m}$ height can be used to observe the precipitation types. Precipitation can be classified into two types of rain, convective and stratiform based on the existence of brightband. MRR observation in Serpong shows that convective rain relatively appears more than stratiform rain during the peak of the dry season, while in the rainy season vice versa. For daily variations, the peak of the convective rain appears at about 15.00-16.00 LT while the stratiform is around 18.00 LT.
\end{abstract}

Keyword : Rain, Convective, Stratiform, Micro Rain Radar

\section{PENDAHULUAN}

Indonesia yang terletak di garis khatulistiwa dan dikelilingi oleh laut mempunyai sistem cuaca yang cukup kompleks. Salah satu parameter untuk mengetahui sistem cuaca yaitu dengan mengamati curah hujan, karena hujan merupakan produk akhir dari sistem cuaca. Salah satu metode untuk mengukur hujan konvensional adalah dengan menggunakan penakar hujan yang dapat menghitung jumlah curah hujan di permukaan.

Dengan berkembangnya teknik penginderaan jauh, presipitasi dapat diukur dengan lebih akurat karena daya jangkaunya yang lebih luas dan dengan resolusi yang lebih baik dibandingkan penakar biasa. Perbedaan penggunaan panjang gelombang menentukan apa yang akan diamati, namun biasanya radar cuaca menggunakan panjang gelombang antara beberapa centimeter sampai puluh centimeter.

Micro Rain Radar (MRR) merupakan salah satu alat yang dapat menghitung curah hujan dengan menggunakan gelombang radio. Beberapa studi untuk membandingkan hasil pengukuran MRR dengan alat lain telah banyak dilakukan. Peters et al. (2002) yang membandingkan pengukuran MRR dengan Cband radar menunjukkan kesesuaian diantara kedua hasil pengukuran tersebut. Kirankumar \& Kunhikrishnan (2013) melakukan evaluasi MRR dengan membandingkan datanya dengan pengukuran disdrometer. Sedangkan di Indonesia, Marzuki et al. (2016) melakukan studi yang sama dengan menggunakan MRR di Bukittinggi (Sumatera Barat) dan Renggono (2017) dengan MRR di Serpong.

Curah hujan pada suatu wilayah berhubungan erat dengan jenis hujannya. Walaupun MRR tidak dapat mengamati hujan secara spasial, namun MRR mampu mempelajari struktur tegak lurus dari hujan secara lebih detil. Penelitian oleh Das et al. (2010) yang melakukan pengamatan struktur vertikal hujan dengan MRR menunjukkan hasil yang cukup baik. Dari struktur vertikal hujan dapat diketahui jenis hujan yang terjadi.

Pada tulisan ini dijelaskan metode pembagian jenis hujan berdasarkan hasil pengamatan dengan MRR. Selain itu juga hasil 
pengamatan hujan dengan MRR selama tahun 2017 di Serpong ditunjukkan dalam bentuk variasi tahunan dan musiman.

\section{METODE}

Penelitian struktur vertikal hujan pada tulisan ini dilakukan dengan menggunakan MRR milik Balai Besar Teknologi Modifikasi Cuaca Badan Pengkajian dan Penerapan Teknologi (BBTMC-BPPT) yang terletak di Serpong, Tangerang Selatan $\left(6.359^{\circ} \mathrm{S}, 106.673^{\circ} \mathrm{E}, 40\right.$ mdpl). Pengamatan dengan MRR di Serpong dilakukan sejak bulan Maret 2016 yang sebelumnya sempat dipasang selama satu bulan (17 Januari - 16 Februari 2016) di Dramaga, Bogor untuk melakukan pengamatan awan secara intensif (Intensive Observation Period/IOP). MRR merupakan sebuah FM-CW Doppler radar dengan panjang gelombang $24 \mathrm{GHz}$ dan daya pancar $50 \mathrm{~mW}$. Dengan sebuah parabola berdiameter $600 \mathrm{~mm}$ dan lebar beam sekitar $1.5^{\circ}$, MRR buatan METEK ini dapat mengamati struktur hujan dengan resolusi 30300meter sebanyak 31step. Spesifikasi detilnya dapat dilihat pada Tabel 1.

Tabel 1. Spesifikasi MRR Serpong

\begin{tabular}{|c|c|}
\hline Radar wavelength & $\Lambda=1.25 \mathrm{~cm}$ \\
\hline Transmit power & $50 \mathrm{~mW}$ \\
\hline Modulation & FM-CW \\
\hline Beam direction & Vertical \\
\hline $\begin{array}{l}\text { Beam width ( } 2 \text { way } 6 \\
\text { dB) }\end{array}$ & $2^{0}$ \\
\hline Antenna & parabolic \\
\hline Radom & No \\
\hline Range resolution & $>10 \mathrm{~m}$ \\
\hline Lowest useful range & $3^{*} \Delta \mathrm{z}$ \\
\hline Number of range gates & 30 \\
\hline Time resolution & $>10 \mathrm{~s}$ \\
\hline $\begin{array}{ll}\text { Spectral } & \text { velocity } \\
\text { resolution } & \end{array}$ & $0.91 \mathrm{~m} / \mathrm{s}$ \\
\hline Nyquist velocity range & $\begin{array}{l}0-12.3 \mathrm{~m} / \mathrm{s} / 0-9.25 \\
\mathrm{~m} / \mathrm{s}\end{array}$ \\
\hline Update range & $\begin{array}{l}\approx 10 \mathrm{~s}^{-1} \\
\approx 6 \mathrm{~s} \text { observation time } \\
\approx 4 \mathrm{~s} \text { data transmission }\end{array}$ \\
\hline $\begin{array}{l}\text { Min. radar reflectivity } \\
(\mathrm{z}=1000 \mathrm{~m}, \Delta \mathrm{z}=100 \mathrm{~m}, \\
\Delta \mathrm{t}=60 \mathrm{~s})\end{array}$ & $-2 \mathrm{dBZ}$ \\
\hline
\end{tabular}

Prinsip kerja dari FM-CW Doppler radar dijelaskan oleh Strauch (1975). Hasil awal dari pengamatan MRR selama IOP dilaporkan oleh Syafira et al. (2016), Tikno et al. (2016) dan Renggono (2017).

Pembagian jenis hujan berdasarkan pengamatan dengan radar biasanya dilakukan dengan melihat kemunculan brightband, yaitu lapisan horisontal dengan reflektivitas yang kuat yang berada di ketinggian dimana kristal es mencair menjadi butir hujan. Jika pada suatu kejadian hujan terdapat brightband, maka hujan yang terjadi digolongkan dalam hujan stratiform, sedangkan hujan selain itu digolongkan dalam hujan konvektif. Keberadaan brightband ini dijelaskan oleh Leary \& Houze (1979) dalam penelitiannya dengan radar di wilayah tropis.

Dengan menggunakan Wind Profiler Radar (WPR), Williams et al. (1995) membuat algoritma untuk membagi kejadian hujan menjadi 4 jenis berdasarkan keberadaan brightband. Di Indonesia dengan menggunakan algoritma yang sama, Renggono et al. (2001) melakukan studi tentang variasi harian dari masing-masing jenis hujan berdasarkan pengamatan dengan Boundary Layer Radar (BLR) yang menggunakan frekuensi $1.3 \mathrm{MHz}$.

Dalam penelitiannya di semenanjung Zingst, Jerman, Peters et al. (2002) menunjukan bahwa keberadaan brightband pada saat hujan dapat terdeteksi oleh MRR. Kemunculan brightband pada ketinggian sekitar 1000-1500m dibarengi dengan perubahan kecepatan jatuh dari hydrometeor. Hasil ini sama seperti yang ditunjukan oleh Williams et al. (1995) yang menggunakan WPR. Karena ketinggian $0^{\circ}$ isotherm di Serpong berada di atas $4000 \mathrm{~m}$, maka MRR diatur resolusinya menjadi $250 \mathrm{~m}$ agar dapat mengamati hujan sampai ketinggian di atas $7500 \mathrm{~m}$. Contoh hasil pengukuran pada saat kejadian hujan tanggal 3 Februari 2016 di Dramaga, Bogor dapat dilihat pada Gambar 1.

Reflektivitas yang kuat dari permukaan sampai di atas $4000 \mathrm{~m}$ tampak pada pukul 10.00 11.00 UTC, sedangkan pada pukul 11.00-12.30 UTC, reflektivitas yang tinggi hanya terlihat pada ketinggian 4250-5000m (Gambar 1-kiri). Struktur reflektivitas yang pertama sesuai dengan karakteristik hujan konvektif, sedangkan yang kedua adalah hujan stratiform. Garis A dan B pada gambar ini masing-masing adalah contoh untuk hujan konvektif dan stratiform. Tiga parameter hasil pengukuran dengan MRR, yaitu reflektivitas, kecepatan jatuh dan LWC ditampikan dalam bentuk grafik profil ketinggian pada gambar di sebelah kanan.

Contoh untuk hujan konvektif diambil dari data hujan pukul 10.40 UTC. Reflektivitas di atas $15 \mathrm{dBZ}$ terlihat sampai ketinggian $3500 \mathrm{~m}$, kecepatan jatuh sampai ketinggian $3500 \mathrm{~m}$ juga cukup besar, yaitu lebih dari $7 \mathrm{~ms}^{-1}$. Akan tetapi nilai LWC yang agak tinggi hanya di permukaan saja (Gambar A).

Hujan stratiform diambil dari data pukul 11.30 UTC. Profil dari masing-masing parameter dapat dilihat pada gambar B. Reflektivitas terlihat menguat pada ketinggian 4000-5000m, perubahan kecepatan antara 5000 dan 4250m mencapai $4 \mathrm{~ms}-1$, dan LWC yang tinggi terlihat diatas $4500 \mathrm{~m}$. Menguatnya reflektivitas dari ketinggian 5500 ke ketinggian $0^{\circ}$ isoterm sejalan dengan melelehnya sebagian butir es di bagian permukaannya yang menyebabkan ukurannya 

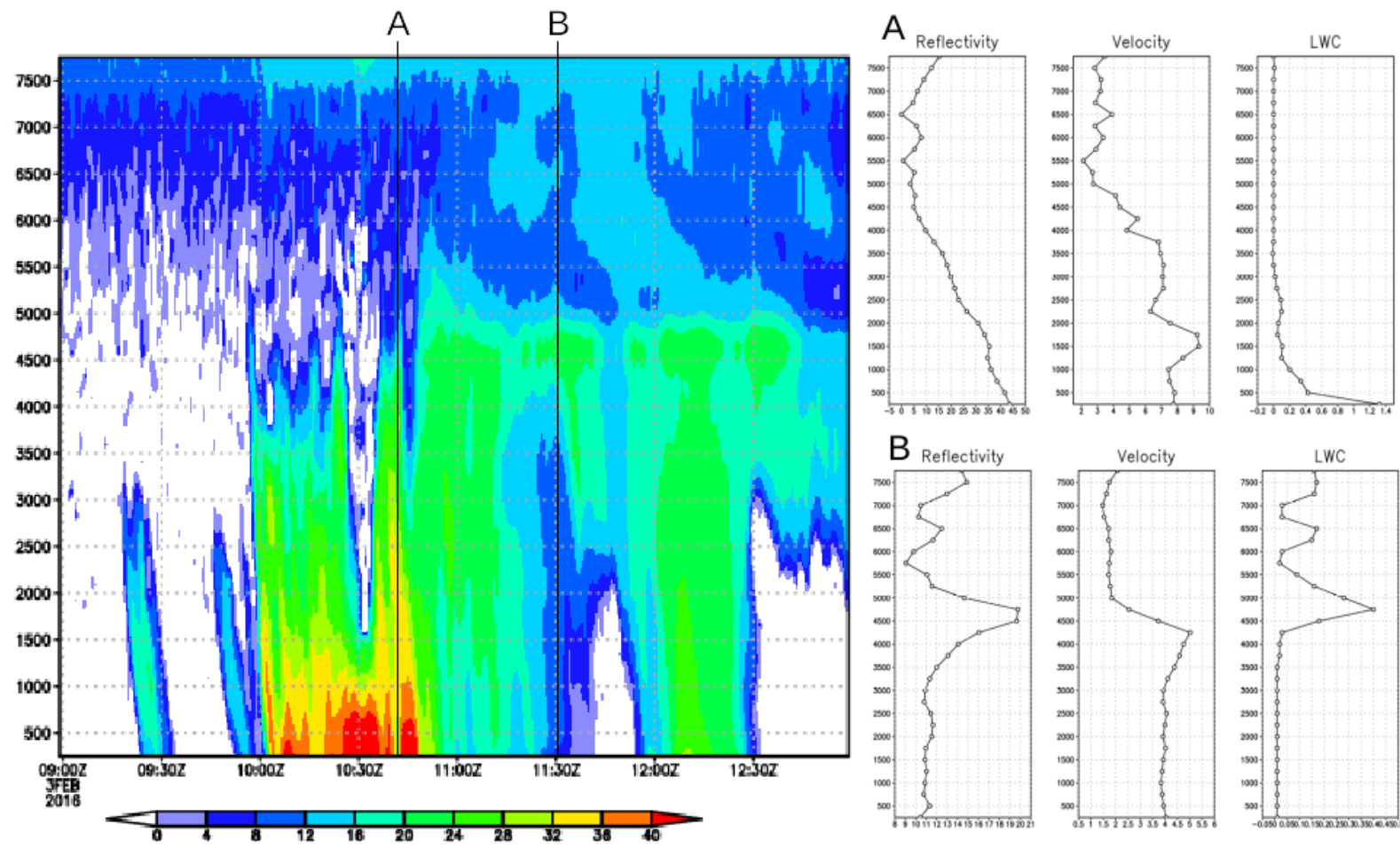

Gambar 1. Reflektivitas MRR untuk kejadian hujan tanggal 14 Februari 2016. (Pada bagian atas adalah jenis hujannya: merah untuk konvektif dan jingga untuk stratiform).

menjadi lebih besar dengan air (yang mempunyai konstanta dielektrik yang lebih tinggi dibandingkan es) melapisi permukaannya. Hal inilah yang membuat nilai reflektivitas radar yang tinggi. Namun saat seluruh es telah meleleh dan menjadi butir hujan, kecepatan jatuh meningkat, hal ini juga membuat butir hujan terpecah menjadi butir yang lebih kecil yang mengakibatkan reflektivitas juga melemah.

Pada tulisan ini, hujan dibagi menjadi dua jenis, yaitu stratiform dan konvektif. Dengan mempertimbangkan hasil pengamatan diatas, dilakukan sedikit modifikasi atas algoritma yang telah dibuat oleh Williams et al. (1995).

Tahapan untuk menentukan jenis awan adalah sebagai berikut:

1. Data MRR yang dianalisis adalah data ratarata setiap menit.

2. Kejadian hujan ditentukan menggunakan data reflektivitas pada ketinggian $500 \mathrm{~m}$ (Reflektivitas $>5 \mathrm{dBZ}$ ).

3. Brightband ditentukan dengan melihat adanya perbedaan kecepatan jatuh antara ketinggian $5000 \mathrm{~m}$ dengan $4250 \mathrm{~m}\left(\Delta \mathrm{v}>4 \mathrm{~ms}^{-1}\right)$.

4. Jika ada brightband, kejadian hujan pada menit tersebut adalah hujan stratiform. Jika tidak ada brightband, dan reflektivitas sampai ketinggian $4000 \mathrm{~m}$ diatas $15 \mathrm{dBZ}$, maka hujan dianggap sebagai konvektif.

\section{HASIL DAN PEMBAHASAN}

\subsection{Klasifikasi Awan Hujan}

Kejadian hujan tanggal 14 Februari 2016 di

Dramaga, Bogor dianalisis. Hasil dari analisis dapat dilihat pada Gambar 2. Kontur pada gambar ini merupakan reflektivitas kejadian hujan dari pukul 6.00 UTC sampai pukul 12.00 UTC. Sedangkan simbol di bagian atas (pada ketinggian 7000 dan 7250) merupakan hasil analisis jenis hujan yang bersesuaian dengan reflektivitas di bawahnya. Warna merah adalah awan konvektif, sedangkan warna jingga adalah stratiform. Pada gambar ini terlihat bahwa antara pukul 6.00-8.00 UTC lebih banyak didominasi oleh hujan konvektif (49 profil), dan antara pukul 8.00-12.00 UTC lebih banyak hujan stratiform (53 profil).

Selama tahun 2017, pengamatan dilakukan di Serpong dengan memasang MRR di atap gedung BBTMC-BPPT. Hasil analisis klasifikasi awan dengan metode yang sama, diperoleh 19922 profil untuk hujan yang terjadi selama tahun 2017. Dari keseluruhan profil tersebut hampir separuhnya adalah stratiform dan separuhnya lagi konvektif. Masing-masing jenis hujan dikelompokan dan di tampilkan dalam CFAD (Contoured Frequency by Altitude Diagram). Warna kontur menunjukkan jumlah data yang mempunyai nilai yang sama.

Pada gambar ini terlihat bahwa reflektivitas yang cukup tinggi untuk konvektif (3.a) banyak terjadi di bawah ketinggian $4000 \mathrm{~m}$, sedangkan di atas $5000 \mathrm{~m}$ reflektivitas tidak terlalu besar. Hal ini mungkin disebabkan karena atenuasi yang tinggi dari hujan di dekat permukaan, seperti yang juga dilaporkan oleh Sara dkk (2016) dalam pengamatannya di Dramaga, Bogor. Kecepatan jatuh pada ketinggian 2000-4000m tersebar antara 4-9 ms $\mathrm{ms}^{-1}$ (3.b) dan LWC di dekat permukaan juga cukup besar (3.c). 
Reflectivity \& Precipitation Type

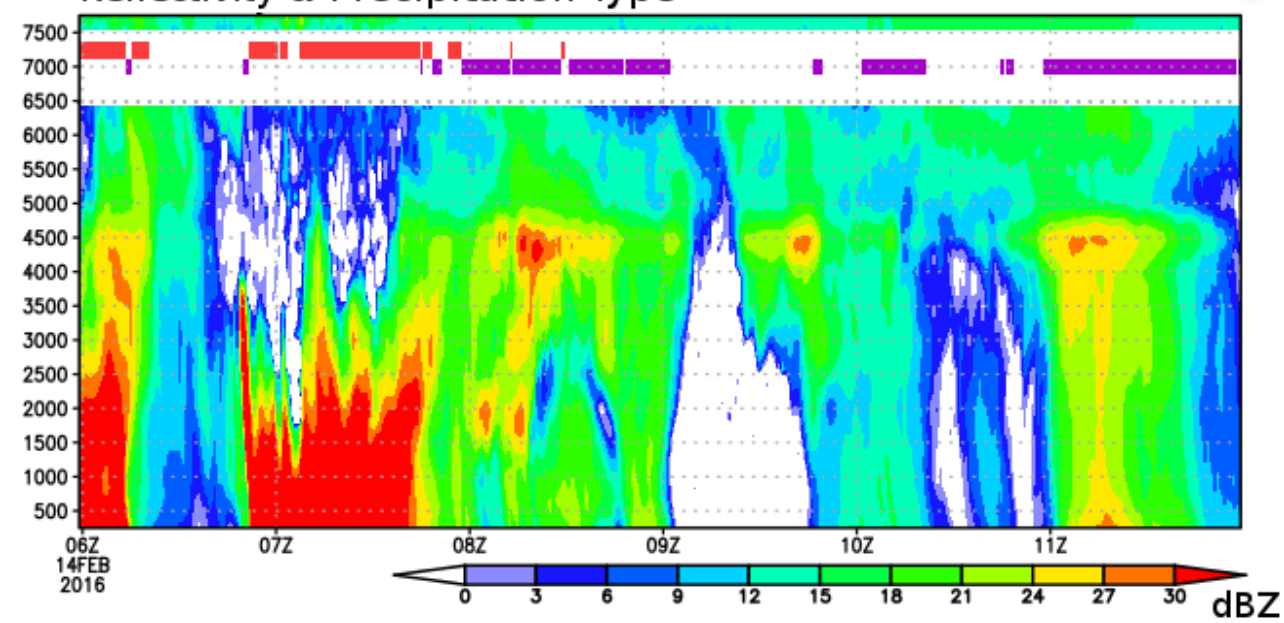

Gambar 2. Reflektivitas MRR untuk kejadian hujan tanggal 14 Februari 2016. (Pada bagian atas adalah jenis hujannya: merah untuk konvektif dan jingga untuk stratiform).
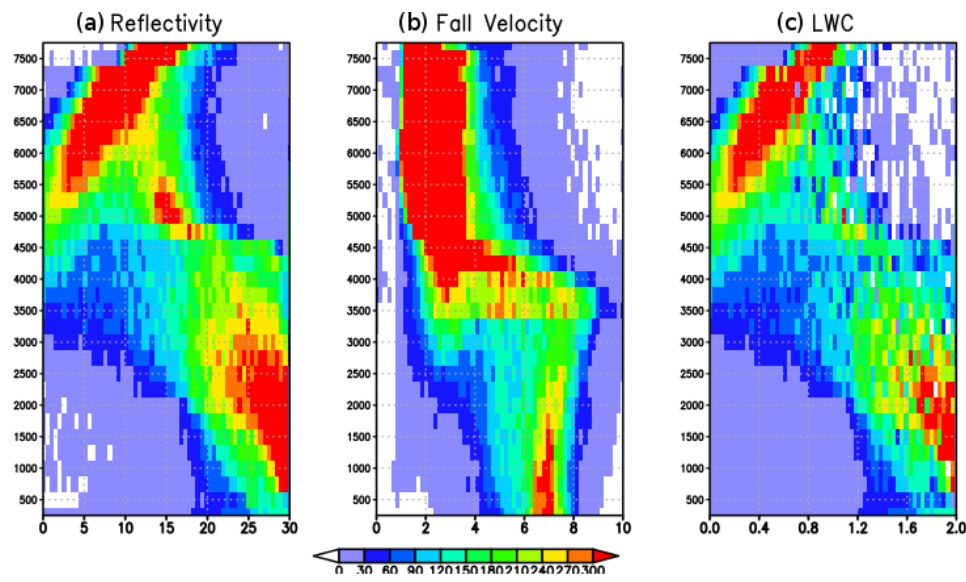

(d) Reflectivity

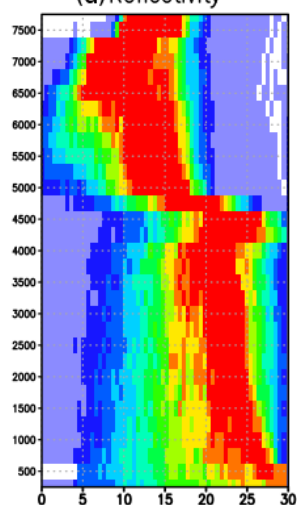

(e) Fall Velocity

(f) LWC
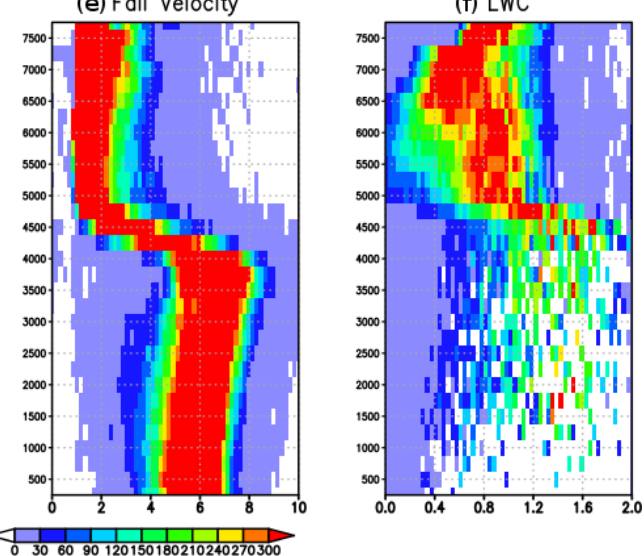

Gambar 3. CFAD dari reflektivitas (a), kecepatan jatuh (b), LWC (c) untuk hujan konvektif, dan reflektivitas (d), kecepatan jatuh (e), LWC (f) untuk hujan stratiform.

Untuk hujan dari awan stratiform, brightband terlihat pada ketinggian 3750-4250m (3.d). Pada ketinggian antara 3500-4500m juga terlihat perbedaan kecepatan jatuh yang cukup besar (3.e) dan terlihat dengan jelas bahwa hampir seluruh profil kecepatan stratiform mengikuti pola tersebut. Untuk nilai LWC, hanya sedikit yang berada di dekat permukaan (3.f).

\subsection{Variasi Tahunan dan Harian}

Pola kemunculan awan hujan sepanjang tahun 2017 dapat dilihat pada Gambar 4. Terlihat jelas bahwa pola hujan tahunan di Serpong (4.a) mempunyai satu puncak musim hujan seperti yang dijelaskan oleh Aldrian \& Susanto (2003) dan Hamada et al. (2002). Pada saat puncak musim hujan, kecuali bulan Februari, terlihat kemunculan awan konvektif lebih sedikit dari pada awan stratiform. Sedangkan pada puncak musim kering yang banyak terlihat adalah awanawan hujan konvektif. Pola seperti ini juga telah dilihat oleh Renggono et al. (2001) dalam pengamatannya menggunakan BLR. 

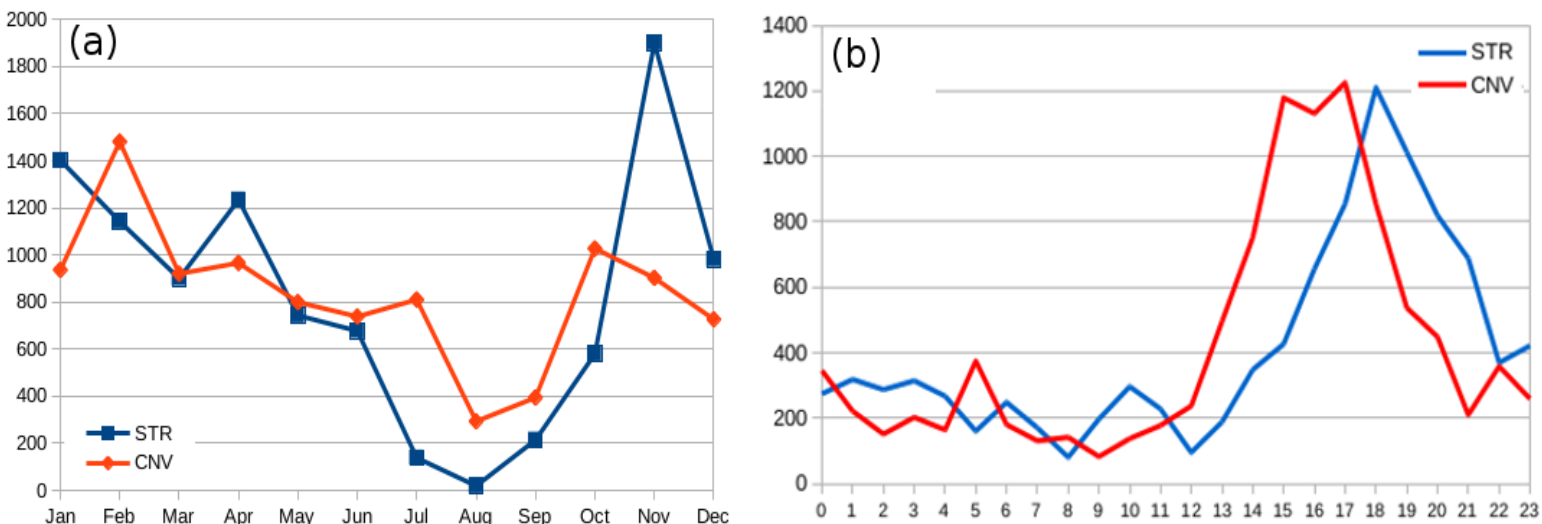

Gambar 4. Variasi tahunan (a), dan variasi harian (b) kemunculan jenis awan hujan di Serpong berdasarkan pengamatan dengan MRR.

Dari variasi hariannya terlihat bahwa kebanyakan kejadian hujan di Serpong muncul setelah pukul 14.00 WIB. Hujan konvektif mempunyai puncak kemunculan lebih awal daripada stratiform, yaitu sekitar pukul 15.0016.00 WIB, sedangkan puncak hujan stratiform muncul sekitar pukul 18.00 WIB. Kemunculan hujan stratiform yang lebih lambat dapat menunjukkan bahwa hujan stratiform ini terbentuk karena proses hidup dari awan itu sendiri. Akan tetapi dalam pengamatan dengan MRR ini tidak terlihat bahwa awan stratiform lebih lama bertahan dibandingkan awan konvektif. Hal ini mungkin disebabkan algoritma pemilihan hujan yang terlalu ketat, sehingga untuk awanawan stratiform yang mempunyai curah hujan yang rendah tidak ikut dianalisis oleh algoritma ini, seperti yang terlihat pada kejadian hujan pada pukul 9.30-10.00 UTC pada gambar 2 .

\section{KESIMPULAN}

Kemampuan MRR untuk mengamati parameter hujan sampai ketinggian $7500 \mathrm{~m}$ menyebabkan alat ini dapat digunakan untuk mempelajari struktur hujan secara lebih detil. Dari parameter reflektivitas dan kecepatan jatuh dapat dibedakan menjadi dua jenis hujan, yaitu konvektif dan stratiform.

Hujan stratiform mempunyai brightband dan mempunyai perubahan kecepatan jatuh yang cukup besar di atas ketinggian $0^{\circ}$ isoterm. Sedangkan hujan konvektif mempunyai reflektivitas dan kecepatan jatuh yang relatif lebih kuat.

Kemunculan hujan konvektif terlihat lebih banyak dibandingkan stratiform pada puncak musim kering. Hal ini mungkin menunjukkan awan yang tumbuh pada musim kering langsung hilang setelah hujan, tidak seperti musim hujan yang setelah terjadi hujan konvektif, dalam proses matinya masih menimbulkan awan-awan stratiform yang bertahan cukup lama. Ini terlihat dari jumlah hujan stratiform yang lebih banyak muncul (dibandingkan konvektif) pada musim hujan. Variasi harian menunjukkan puncak kemunculan hujan konvektif sekitar pukul 15.0016.00 WIB, sedangkan hujan stratiform sekitar pukul 18.00 WIB.

\section{DAFTAR PUSTAKA}

Aldrian, E., Susanto, R.D. (2003). Identification of Three Dominant Rainfall Regions within Indonesia and Their Relationship to Sea Surface Temperature. International Journal of Climatology, 23(12), 1435-1452. doi: $10.1002 / j$ joc. 950

Cha, J.-W., Chang, K.-H., Yum, S.S., Choi, Y.-J. (2009). Comparison of the Bright Band Characteristics Measured by Micro Rain Radar (MRR) at a Mountain and a Coastal Site in South Korea. Advances Atmospheric Sciences, 26(2), 211-221. doi: 10.1007/s00376-009-0211-0

Das, S., Shukla, A.K., Maitra, A. (2010). Investigation of Vertical Profile or Rain Microstructure at Ahmedabad in Indian Tropical Region. Advances In Space Reasearch. 45(10), 1235-1243. doi: 10.1016/j.asr.2010.01.001

Hamada J.-I., Yamanaka, M.D., Matsumoto, J., Fukao, S., Winarso, P.A., Sribimawati, T. (2002). Spatial and Temporal Variations of the Rainy Season over Indonesia and their Link to ENSO. Journal of the Meteorological Society of Japan, 80(2), 285-310. doi: 10.2151/jmsj.80.285

Kirankumar, N.V.P., Kunhikrishnan, P.K. (2013). Evaluation of Performance of Micro Rain Radar over the Tropical Coastal Station Thumba $\left(8.5^{\circ} \mathrm{N}, \quad 76.9^{\circ} \mathrm{E}\right)$. Atmospheric Research, 134, 56-63. doi: 10.1016/j.atmosres.2013.07.018

Leary, C.A., Houze, R.A. (1979). Melting and Evaporation of Hydrometeors in Precipitation from the Anvil Clouds of Deep Tropical Convection. Journal Of The Atmospheric Science, 36, 669-679.

Marzuki., Hashiguchi, H., Shimomai, T., Rahayu, I., Vonnisa, M., Afdal. (2016). Performance Evaluation of Micro Rain Radar over 
Sumatra Through Comparison with Disdrometer and Wind Profiler. Progress In Electromagnetics Research M, 50, 33-46. doi: 10.2528/PIERM16072808

Renggono, F., Hashiguchi, H., Fukao, S., Yamanaka, M.D., Ogino, S.Y., Okamoto, N., Murata, F., Sitorus, B.P., Kudsy, M., Kartasasmita, M., Ibrahim, G. (2001). Precipitating Clouds Observed by $1.3-\mathrm{GHz}$ Boundary Layer Radars in Equatorial Indonesia. Annales Geophysicae, 19(8), 889-897.

Renggono, F. (2002). Analisis Karakteristik Hujan dengan Disdrometer. Jurnal Sains \& Teknologi Modifikasi Cuaca, 3(2), 141-147.

Renggono, F. (2017). Pengamatan Kejadian Hujan dengan Disdrometer dan Micro Rain Radar di Sepong. Jurnal Sains \& Teknologi Modifikasi Cuaca, 18(1), 1-7. doi: 10.29122/jstmc.v18i1.2199

Peters, G., Fischer, B., Andersson, T. (2002). Rain Observations with a Vertically Looking Micro Rain Radar (MRR). Boreal Environment Research, 7, 353-362.

Strauch, R.G., Campbell, W.C., Chadwick, R.B., Moran, K.P. (1975). FM-CW Boundary
Layer Radar with Doppler Capability, NOAA Techn. Rep. ERL 329-WPL 39, Dept. of Commerce.

Syafira, S.A., Syaifullah, M.D., Renggono, F. (2016), Karakteristik Hujan dan Awan Penghasil Curah Hujan Tinggi Berdasarkan Data Micro Rain Radar (Studi Kasus : Wilayah Dramaga, Bogor). Jurnal Sains \& Teknologi Modifikasi Cuaca, 17(1), 27-35.

Tikno, S., Yahya, R.B., Syafira, S.A. (2016). Perbandingan Profil Hujan Vertikal Radar Cuaca dengan Micro Rain Radar Selama Kejadian Hujan Sedang (Studi Kasus: Intensive Observation Period 2016). Jurnal Sains \& Teknologi Modifikasi Cuaca, 17(2), 57-64.

Williams, C.R., Ecklund, W.L., Gage, K.S. (1995). Classification of Precipitating Clouds in the Tropics Using 915-MHz Wind Profiler. Journal of Atmospheric and Oceanic Technology, 12(5), 996-1012. doi: 10.1175/1520-

0426(1995)012<0996:COPCIT>2.0.CO;2 